\title{
PENGARUH VARIASI JUMLAH LAPISAN FIBERGLASS DAN ANYAMAN BAMBU TERHADAP KEKUATAN BENDING KOMPOSIT DENGAN METODE VACUUM ASSISTED RESIN INFUSSION (VARI)
}

\author{
Achmad Zainuri", Agus Dwi Catur dan M. Zazali \\ Teknik Mesin Fakultas Teknik Universitas Mataram \\ J1. Majapahit 62 Mataram \\ *Email: achmadzainuri70@yahoo.co.id.
}

\begin{abstract}
The objective of this research is to obtain the bending properties of composite material produced by VARI method, and to get analysis of polyester resin distribution time on the layer of fiberglass composite and bamboo woven strip.

The process of making composites varies, but the process of making this research is the process of Vacuum Assisted Resin Infusion (VARI). In the VARI process, dry fiber is placed between the fixmold and plactic bag, then the resin is injected after the chamber inside the low-pressure plastic bag and the process continues until all parts of the fiber are wetted by the resin.

From the results of research, testing and discussion of bending test results that have been done then can be drawn conclusions include: Variation of the number of reinforcement layer on VARI method will affect the value of bending strength of composite. By using the VARI method The highest average value of bending stress occurs in variation 4 (206,69 MPa), while the lowest occurs in variation $1(42,83 \mathrm{MPa})$, and the time required for the distribution of resin varies in time variation 1 which takes 5 minutes 02 seconds, while for variation 4 takes 8 minutes 3 seconds.
\end{abstract}

Keywords: composites, VARI method, glass fiber, bending test

\section{PENDAHULUAN}

Kebanyakan teknologi modern memerlukan bahan dengan kombinasi sifat-sifat yang luar biasa yang tidak dapat diperoleh pada bahanbahan lazim seperti logam besi, keramik, dan bahan polimer. Seperti penggunaan material dalam bidang pesawat terbang, perumahan, perkapalan, kendaraan dan industri pengangkutan. Karena bidang-bidang tersebut membutuhkan masa jenis yang rendah, kekuatan bending yang tinggi, kekuatan tarik yang tinggi, dan tahan korosi, maka material komposit yang menjadi alternatif.

Proses pembuatan komposit sendiri adalah bermacam-macam, namun proses pembuatan komposit yang dipilih pada penelitian ini adalah proses Vacum Assisted Resin Infusion (VARI). Dalam proses VARI, fiber kering diletakkan antara fixmold dan plactik bag, kemudian resin diinjeksikan setelah ruang di dalam plastic bag bertekanan rendah dan proses berlanjut sampai seluruh bagian fiber terbasahi oleh resin. Dibandingkan dengan proses konvensional seperti misalnya RTM (Resin Transfer Molding), proses VARI lebih ekonomis karena tidak melibatkan tekanan tinggi. Selain itu, proses VARI dapat mengurangi efek pengotoran yang banyak terjadi pada proses non vakum dan menimbulkan kurang optimalnya sifat material komposit [A. Goren, . Atas. 2008].

Dalam penelitian ini dilakukan variasi jumlah lapisan komposit fiberglass dan serat bambu untuk mencari perbedaan sifat material hasil dari distribusi resin polyester pada proses VARI. Karena masing - masing lapisan kompoit memiliki jarak persebaran resin polyester yang tidak sama, sehingga dapat membuat void yang berbeda antara tiap variasi lapisan. Perbedaan void yang terjadi dapat mempengaruhi sifat dari material komposit sehingga diperlukan pengujian bending untuk mengetahui sifat material pada setiap spesimen hasil dari proses VARI pada tiap variasi serat gelas dan serat bambu.

\section{Tinjauan Pustaka}

Nugroho, (2016) meneliti bahwa jumlah lapisan fiberglass pada komposit dengan menggunakan matrik epoksi dapat mempengaruhi kekuatan tarik yang dihasilkan. Matrik tanpa serat memiliki kekuatan tarik 44,56 $\mathrm{MPa}$, komposit serat 2 lapis kekuatan tarik 31,79 $\mathrm{MPa}$, serat 3 lapis kekuatan tarik 40,18 MPa, serat 4 lapis kekuatan tarik 56,42 $\mathrm{MPa}$, dan serat 5 lapis kekuatan tarik 51,34 
MPa. Penambahan serat juga berpengaruh pada regangan komposit. Pada pengujian resin tanpa serat diperoleh regangan sebesar $2,15 \%$ dan pada komposit dengan serat diperoleh regangan sebesar $1,21 \%$.

Djamil, S (2017) meneliti kekuatan luluh komposit jenis anyaman bambu dengan perlakuan alkali dan tanpa alkali. Jenis anyaman plain sebelum proses alkali kekuatan luluh $15,60 \pm 2,24 \mathrm{MPa}$, setelah proses alkali kekuatan luluh 18,80 $\pm 2,13 \mathrm{MPa}$. Untuk jenis anyaman twill sebelum proses alkali kekuatan luluh $24,48 \pm 3,92 \mathrm{MPa}$, setelah proses alkali kekuatan luluh 29,90 $\pm 2,27 \mathrm{MPa}$. Untuk jenis anyaman plain sebelum proses alkali kekuatan tarik maksimum 20,94 $\pm 3,69 \mathrm{MPa}$, setelah proses alkali kekuatan tarik maksimum 25,53 \pm 3,94 MPa. Untuk jenis anyaman twill sebelum proses alkali kekuatan tarik maksimum 30,18 \pm 7,26 $\mathrm{MPa}$, setelah proses alkali kekuatan tarik maksimum 35,15 $\pm 2,81 \mathrm{MPa}$. Untuk jenis anyaman plain sebelum proses alkali regangan $2,29 \pm 0,36 \%$, setelah proses alkali regangan $2,47 \pm 0,25 \%$. 6) Untuk jenis anyaman twill sebelum proses alkali regangan $2,27 \pm 0,40 \%$, setelah proses alkali regangan 2,27 $\pm 0,40 \%$.

Febriyanto, S (2011) meneliti bahwa material komposit sandwich yang dibuat menggunakan metode VARI dengan menggunakan material inti berupa $P U$-foam dan material kulit berupa E-glass memiliki kekuatan mekanik dengan nilai kekuatan tarik rata-rata berkisar anatara 7 sampai $30 \mathrm{MPa}$ dan nilai kekuatan tekan rata-rata antara 4 sampai $6 \mathrm{MPa}$. Nilai dari kekuatan mekanik ini merupakan nilai yang cukup baik untuk diaplikasikan pada pembuatan komponen kapal bersayap. Terutama untuk kuat tekan yang memiliki nilai sebesar satu angka lebih besar dari data pengujian pada penelitian acuan. Penggunaan material $P U$-foam ternyata dapat meningkatkan stabilitas dari material komposit sandwich, kuat tarik dan tekan yang lebih baik, serta tahanan geser yang dapat dirancang sedemikian rupa sesuai kebutuhan.

\section{Landasan Teori}

Kekuatan bending atau kekuatan lengkung adalah tegangan bending terbesar yang dapat diterima akibat pembebanan luar tanpa mengalami kegagalan. Akibat tegangan bending, pada bagian atas spesimen akan mengalami tekanan, dan bagian bawah akan mengalami tegangan tarik. Material komposit kekuatan tekannya lebih tinggi terhadap tegangan tariknya. Kegagalan yang terjadi akibat pengujian bending, komposit akan mengalami patah pada bagian bawah yang disebabkan karena tidak mampu menahan tegangan tarik yang diterima.

Kekuatan bending $(\sigma)$ suatu material dapat dihitung dengan persamaan berikut :

$$
\sigma=\frac{3 P L}{2 b d^{2}}
$$

Keterangan :

$\mathrm{P}=$ Beban $(\mathrm{N})$

$\mathrm{b}=$ Lebar batang uji $(\mathrm{mm})$

$\mathrm{d}=$ Tebal batang uji $(\mathrm{mm})$

Pengujian bending mengacu pada standart ASTM D790, dengan dimensi sesuai dengan gambar 1.

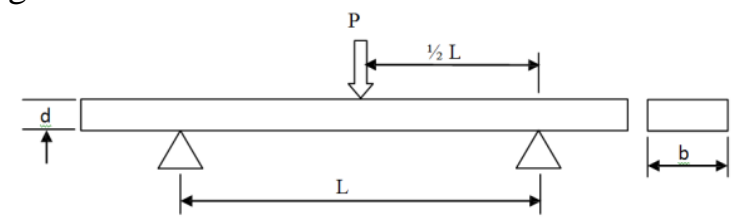

Gambar 1: Spesimen three point bending

\section{METODE PENELITIAN}

Alat yang digunakan dalam penelitian ini adalah:

1. Alat uji bending tensilon.

2. Kamera digital dengan resolusi $8 \mathrm{MP}$, digunakan untuk mengambil gambar penelitian.

3. Pompa vakum, digunakan untuk memvakum resin poliester sehingga terdistribusi dalam cetakan

4. Selang, digunakan untuk mengalirkan resin poliester dari toples ke cetakan dan ke pompa vakum.

5. Plastik bening, digunakan untuk penutup atas cetakan.

6. Peel-plydigunakan untuk membantu pendisribusian resin pada cetakan.

7. Tacki tape, digunakan untuk menyatukan cetakan dengan plastik bening agar tidak terjadi kebocoran.

Bahan yang digunakan dalam penelitian ini sebagai berikut:

1. Resin polyester, digunakan sebagai bahan yang akan mengikat serat.

2. Katalis, digunakan untuk memperceapat reaksi pengerasan pada resin

3. Serat fiberglas jenis E-Glass dengan anyaman halus (woven roving 200) 
dengan densitas serat $2,54 \mathrm{~g} / \mathrm{cm}^{3}$ (Gibson, 1994).

4. Serat anyaman bambu yang digunakan adalah serat bambu Apus atau bambu tali. Batangnya dapat mencapai tinggi antara 8-11 $\mathrm{m}$ dengan panjang ruas $45-65 \mathrm{~cm}$, berdiameter $5-8 \mathrm{~cm}$ dan tebal dinding 13 $15 \mathrm{~mm}$.

5. Larutan $\mathrm{NaOH}$ dengan konsentrasi $\mathrm{NaOH}$ $5 \%$ (berat).

\section{Proses Pembuatan plat komposit.}

a. Bahan yang digunakan adalah resin polyester sebagai matrik dan fiberglass dan anyaman bambu sebagai serat. Serat fiberglass dan serat bambu dipotong dengan ukuran panjang $300 \mathrm{~mm}$ dan lebar $250 \mathrm{~mm}$ seperti pada Gambar 2.a dan 2.b.

b. Setelah itu resin dituang pada gelas penampung dan diaduk-aduk. Siapkan selang, cetakan, pompa vakum, dan alat yang lain yang akan digunakan. Lalu taruh serat fiberglass dan serat bambu yang sudah dipotong sesuai ukuran di atas cetakan. Kemudian plastik ditaruh di atas fiberglass lalu pompa vacuum dihidupkan untuk memvakum cetakan tersebut agar udara terbuang keluar dari cetakan.

c. Kemudian selang sebagai perantara distribusi resin dipasang antara gelas penampung resin dan cetakan. Selanjutnya vakum dihidupkan lagi agar resin terdistribusi merata pada cetakan, lalu catat waktu pendistribusian dari awal menghidupkan vakum sampai vakum dimatikan. Tunggu beberapa menit agar resin yang telah menyebar ke cetakan kering, setelah itu keluarkan hasil cetakan tadi dari cetakan seperti pada Gambar 3.

d. Kemudian ulangi proses tersebut sebanyak empat kali percobaan. Adapun yang membedakan pada setiap percobaan adalah banyak lapisan serat fiberglass dengan satu anyaman bambu.

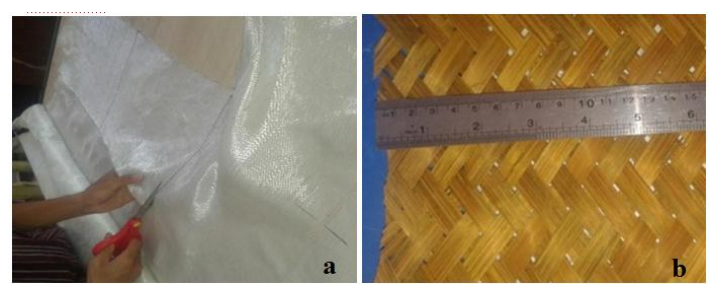

Gambar 2. (a) Fiberglass dan (b) Anyaman bambu

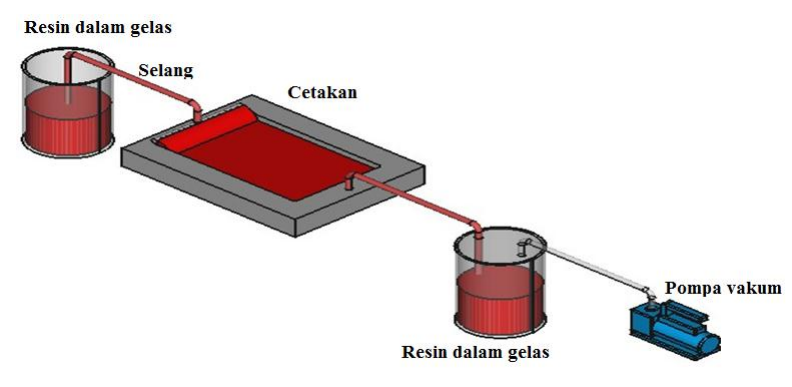

Gambar 3. Proses pembuatan spesimen

\section{Pengujian Bending}

Pengujian bending mengacu pada standart ASTM D790, dengan dimensi sesuai dengan Gambar 4.

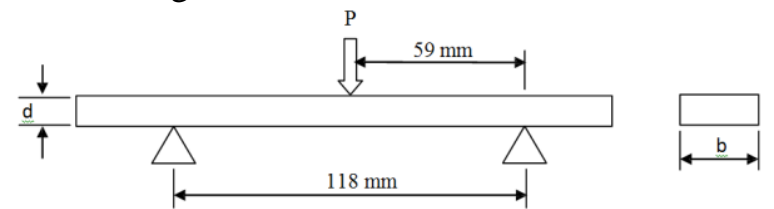

Gambar 4. Dimensi spesimen uji bending.

\section{HASIL DAN PEMBAHASAN}

Hasil pengujian bending komposit dengan berbagai variasi jumlah strip fiberglass dan anyaman bambu dapat dilihat pada Tabel 1 dan grafik pada Gambar 5.

Table 1: Hasil pengujian bending

\begin{tabular}{|c|c|c|c|c|c|}
\hline $\begin{array}{c}\text { Spe } \\
\text { sim }\end{array}$ & $\begin{array}{c}\mathrm{L} \\
(\mathrm{mm})\end{array}$ & $\begin{array}{c}\mathrm{d} \\
(\mathrm{mm})\end{array}$ & $\begin{array}{c}\mathrm{b} \\
(\mathrm{mm})\end{array}$ & $\begin{array}{c}\text { Pmax } \\
(\mathrm{N})\end{array}$ & $\begin{array}{c}\sigma \mathrm{b} \\
(\mathrm{Mpa})\end{array}$ \\
\hline V1 & 118 & 2,9 & 15,8 & 33,33 & 42,83 \\
\hline V2 & 118 & 3,2 & 15,1 & 71,87 & 95,31 \\
\hline V3 & 118 & 3,3 & 15,7 & 147,21 & 180,17 \\
\hline V4 & 118 & 3,7 & 15,8 & 185,02 & 206,69 \\
\hline
\end{tabular}

Keterangan:

$\mathrm{V} 1$ = Variasi fiberglass anyaman bambu fiberglass.

$\mathrm{V} 2$ = Variasi fiberglass fiberglass anyaman bambu fiberglass fiberglass.

$\mathrm{V} 3$ = Variasi fiberglass fiberglass fiberglass anyaman bambu fiberglass fiberglass

Fiberglass.

V4 = Variasi fiberglass fiberglass fiberglass fiberglass anyaman bambu fiberglass

Fiberglass fiberglass fiberglass. 


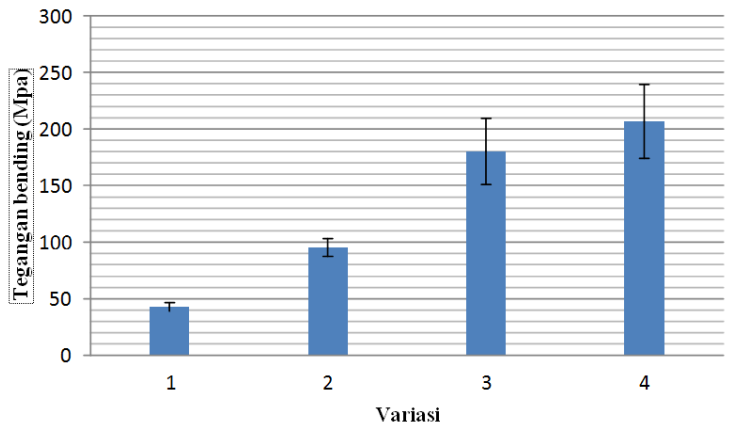

Gambar 5. Tegangan bending rata-rata pada berbagai variasi anyaman serat.

Spesimen awal dan yang telah mengalami deformasi setelah dilakukan uji bending dapat dilihat pada Gambar 6 di bawah ini.
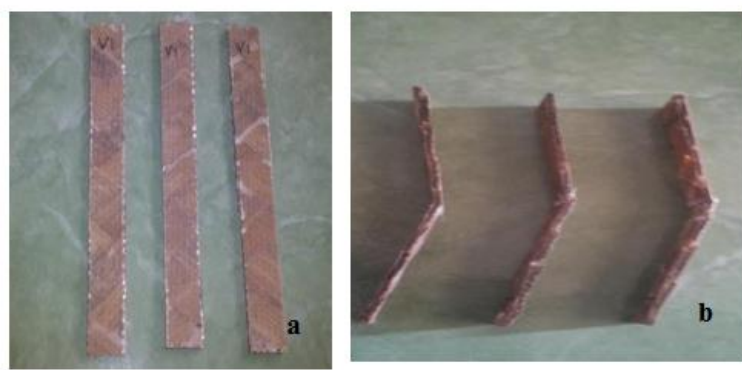

Gambar 6. (a) Spesimen awal variasi 1 dan (b) Spesimen setelah uji bending.

Dari Tabel 1 dan Gambar 5 di atas dapat disimpulkan bahwa tegangan bending rata-rata komposit tertinggi sebesar 206,69 $\mathrm{MPa}$ diperoleh pada variasi V4. Sedangkan tegangan bending rata-rata komposit terendah sebesar 42,83 MPa diperoleh pada variasi V1. Pada grafik Gambar 5 terlihat bahwa tegangan bending rata-rata mengalami kenaikan secara linier dengan bertambahnya variasi jumlah serat fiberglass. Sehingga hasil ini sangat baik jika diterapkan untuk konstruksi pada kapal, otomotif, perumahan, dan lain-lain bahkan untuk pesawat terbang.

Dari Gambar 6 (b) menampakkan hasil patahan atau kegagalan pada pengujian bending komposit, di mana patahan terjadi di bagian bawah yang awal mulanya mengalami retak atau lepas dari ikatannya terhadap serat didalamnya. Pada umumnya kelemahan komposit terhadap beban bending terletak pada bagian komposit yang belum merata pemampatanya antara serat dan resinya dibagian bawah pada spesimen. Pada lapisan ini mempunyai kekuatan tarik maksimum dan akan mengalami kegagalan paling awal karena tidak mampu menahan tegangan tarik pada bagian bawah komposit, sehingga akan terjadi retak lebih awal. Kekuatan yang menahan beban maksimum terjadi pada bagian komposit yang ada didalamnya, yang banyak terjadi pencampuran antara serat dan resin secara merata. Setelah dibagian dalamn ya tidak mampu menahan beban maka di bagian bawah tidak mampu menahan beban, maka akan terjadi retakan pada bagian bawah spesimen tersebut, dan merupakan retakan awal pada komposit.

\section{KESIMPULAN}

Dari hasil penelitian ini, maka dapat diambil kesimpulan sebagai berikut :

1. Variasi jumlah lapisan fiberglass dan serat bambu sebagai penguat komposit dengan metode VARI berpengaruh terhadap nilai kekuatan bending. Nilai tegangan bending rata-rata tertinggi terjadi pada variasi 4 yaitu sebesar (206,69MPa), sedangkan yang terendah terjadi pada variasil yaitu sebesar $(42,83 \mathrm{MPa})$.

2. Dengan menggunakan metode VARI waktu yang dibutuhkan untuk pendistribusian resin bervariasi yaitu pada variasi 1 waktu yang dibutuhkan 5 menit 02 detik, sedangkan untuk variasi 4 membutuhkan waktu 8 menit 03 detik.

\section{DAFTAR PUSTAKA}

A. Goren, . Atas. 2008. Manufacturing of polymer matrix composites using vacuum assited resin infusion moulding, http://www.archivesme.org/vol.342/34210.p df.

ASTM D790, Standard Test Methods for Flexural Properties of Unreinforced and Reinforced Plastics and Electrical Insulating Materials

Djamil,S. and Irawan,P.A. 2017. Karakteristik Mekanik Komposit Serat Bambu Kontinyu Dengan Perlakuan Alkali, Jurnal POROS, Volume 15 Nomor 1, Edisi Mei 2017, hal.69 -75 .

Febriyanto, S. 2011. Penggunaan metode vacuum assisted resin infusion pada bahan uji komposit sandwich untuk aplikasi kapal bersayap wise-8, Skripsi, Fisika FMIPA UI Depok.

Nugroho, Y.D. 2016. Karakteristik komposit serat glass dengan variasi jumlah lapisan serat, Skripsi, Teknik Mesin FST USD Yogyakarta. 